Table 1. Pediatric patients with diagnosis other than biliary atresia.

\begin{tabular}{|c|c|c|c|}
\hline * & Number & Survival $>8$ months & Alive now** \\
\hline Chronic aggressive hepatitis & $9 *$ & $3(33 \%)$ & $2\left(2 / 3,1 \frac{1}{2}\right.$ years $)$ \\
\hline Hepatoma & 3 & $2(67 \%)$ & 0 \\
\hline Wilson's disease & 2 & $2(100 \%)$ & $2\left(4 \frac{1}{4}, 6\right.$ years $)$ \\
\hline Congenital biliary cirrhosis & 1 & $1(100 \%)$ & 1 (3 years) \\
\hline Alpha-1-antitrypsin deficiency & 1 & $1(100 \%)$ & 1 ( $1 \frac{1}{2}$ years) \\
\hline
\end{tabular}

* None of these 9 patients was HBsAg positive.

** The three late deaths were after 13, 14 and 26 months (see text and table 4 for causes).

children, who were 7,11, 11 and 15 years old (OT 80, 26, 67 and 43*), were diagnosed as having intrahepatic atresia largely because of their long survival. Histopathologically, these 4 livers showed a micronodular biliary cirrhosis compatible with congenital intrahepatic biliary atresia. Two of the 4 livers also contained liver cell carcinomas (hepatomas); only one such malignancy was found in the other 36 patients suffering from extrahepatic biliary atresia.

Excluding the four oldest children, the collective age of the other $36 \mathrm{pa}-$ tients with biliary atresia was $31.3 \pm 15.7$ (S.D.) months (range 3 to 67 months).

Although they will not be considered in this report, it is worth mentioning that the 37 adult patients treated during this same time were $39.0 \pm 11.1$ (S.D.) years old (range 21 to 68 years). Their most frequent diagnoses were primary hepatic malignancy, chronic aggressive hepatitis and alcoholic cirrhosis.

\section{MANAGEMENT PRINCIPLES}

Most aspects of the care of these patients have been described (7). Here, a few details will be mentioned.

In recent years, only stable brain dead donors have been accepted. Preliminary arteriography has been routinely performed. Complicated preservation devices are no longer used for the grafts. With almost all infant and

* These orthotopic transplant (OT) numbers are frequently given so the reader may follow given patients through different publications from our center. This method of identification has been used since 1969 (7). 
child donors, the only preservation used has been perfusion with a chilled electrolyte solution through the portal vein just before and after liver removal. To protect the larger livers of adolescents and adults, these donors are often placed on cardiopulmonary bypass and cooled by means of a heat exchanger preparatory to a final infusion with cold electrolyte solution (7).

HL-A typing was obtained on all donors and recipients since 1964, but the match was not used as an instrument of donor-recipient matching. In 51 of the 54 pediatric cases in which typing data were obtained (table 2), major

Table 2. HL-A typing of primary grafts in 56 pediatric cases.

\begin{tabular}{lccl}
\hline Match* & No. & Survival >8 months & Alive now \\
\cline { 2 - 4 } A & $1^{* *}$ & $1(100 \%)$ & 0 \\
B & 2 & $1(50 \%)$ & 0 \\
C & 8 & $3(38 \%)$ & $2(25 \%)$ \\
D & 16 & $3(19 \%)$ & $2(13 \%)$ \\
E & 25 & $11(44 \%)$ & $9(36 \%)$ \\
F & 2 & 0 & 0 \\
Not done & 2 & $1(50 \%)$ & 0 \\
Total & 56 & $20(36 \%)$ & $13(23 \%)$ \\
\hline
\end{tabular}

* A-Match: HL-A identity between recipient and donor.

B-Match: Compatibility between donor and recipient, but fewer antigens determined in the donor.

C-Match: One antigen incompatible.

D-Match: Two antigens incompatible.

E-Match: Three or four antigens incompatible.

F-Match: ABO violation or positive cytotoxic crossmatch.

** Retransplanted after 68 days with $\mathrm{C}$-match graft. Thus the extended survival reflects the result with the second or less well matched graft.

incompatibilities were present. The presence and severity of incompatibilities did not seem to influence the outcome, although the force of such a conclusion was weakened by the fact that good matches were a rarity.

Preformed anti-red cell isoagglutinins and leukocyte cytotoxins are apparently less injurious for liver grafts as compared ta kidneys. These antibodies, which immediately destroy many renal homografts that are transplanted in violation of a 'positive crossmatch' $(4,7)$ do not usually cause a comparable hyperacute rejection of the liver (5). In two patients of the pediatric series, liver transplantation was carried out in confrontation of such preformed antibodies (table 2).

One significant change has been made in the technique of transplantation. 


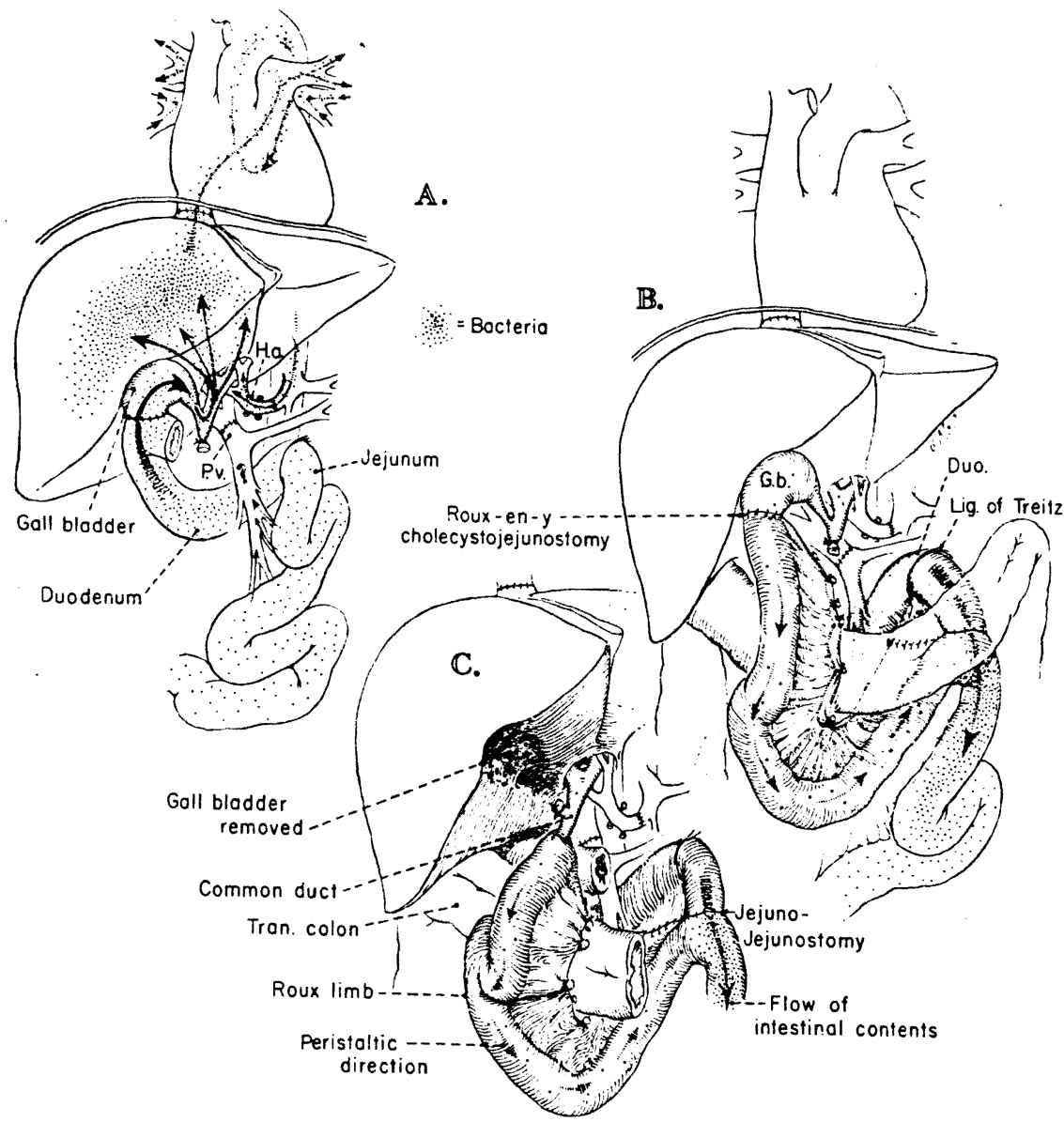

Fig. 1. Commonly used methods of biliary reconstruction. (A) Cholecystoduodenostomy. This extremely simple operation probably carries the greatest risk of graft infection. (B) Roux-en-Y cholecystojejunostomy. This operation protects from hepatic sepsis by placing the new liver outside the main gastrointestinal stream. The isoperistaltic limb is made at least 18 inches long. (C) Roux-en-Y choledochojejunostomy. The end-to-end duct-to-bowel anastomosis is simple if the duct is dilated, as would be the case if a conversion became necessary from $B$ to $C$ because of biliary obstruction. If the common duct is not dilated, the end of the Roux limb is closed and the common duct is anastomosed to the side of the jejunum an inch or so from the tip. (By permission of Transplant. Proc. 6: 129,1974 .)

Provision for graft biliary drainage in most of our early experience was with cholecystoduodenostomy after ligation of the common duct (fig. 1A). Since November 1973; the gall bladder usually has been anastomosed to the je- 
junum by the Roux-en-Y technique (fig. 1B), thus placing the transplant outside the main continuity of the gastrointestinal tract. In a few cases, choledochojejunostomy (fig. 1C) or choledochocholedochostomy with Ttube splinting has been used instead after removal of the gall bladder.

Splenectomy was carried out at the time of transplantation or had been performed previously ( 3 cases) in 42 of the first 51 pediatric patients, being omitted only if it seemed excessively dangerous. In the last five cases of this report, splenectomy was omitted.

Triple agent immunosuppression with azathioprine, prednisone and horse antilymphocyte globulin (ALG) has been standard treatment for most cases since 1966 (7). If hepatotoxicity with azathioprine is suspected, cyclophosphamide may be substituted with the expectation of a comparable therapeutic effect (8).

\section{RESULTS IN PEDIATRIC CASES}

\section{Other than Biliary Atresia}

Mortality in the first half year. Seven of the 16 patients died from one to 188 days after operation (table 3 ). The longest survivor amongst the early deaths was a 15 year old girl (OT 65). She developed inexorable rejection of her first graft. After 157 days, retransplantation was carried out. She died one month later with a multiplicity of complications including intra-abdominal infection, pneumonitis and pulmonary insufficiency. Total survival was 188 days. Histopathologic analysis of the successive grafts showed that the first transplant was severely damaged by rejection while the only damage to the second graft was chronic venous congestion. By 37 days the first graft was undergoing cellular rejection and the portal tracts were densely infiltrated by lymphoid cells, about 20 per cent of which had pyroninophilic cytoplasm. By 147 days there was loss of bile ductules and obstruction of hepatic arterioles and small arteries by fibrous intimal thickening. When the graft was removed at 157 day's there was marked centrilobular cholestasis and frequent scattered areas of old ischemic damage and recent infarction, At autopsy, the second graft had no evidence of rejection.

The second longest survivor amongst those who died early was a 15 year old boy whose homograft was eventually invaded and destroyed in 143 days by metastases from the hepatoma which had been the original disease in the excised native liver (OT 23).

Omitting the foregoing recipients with survivals of 188 and 143 days, the 
T. Г. STARZL ET AL.

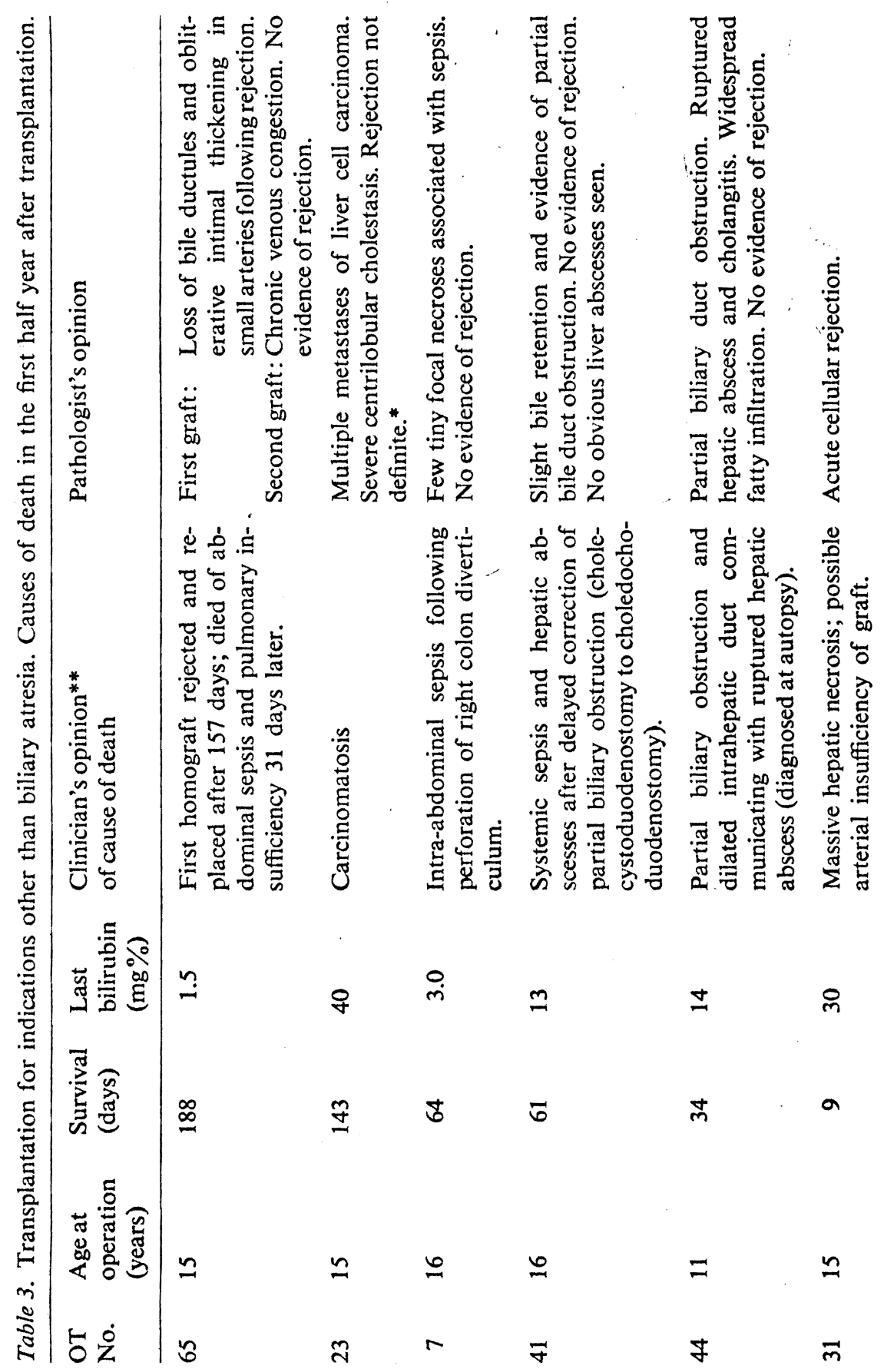




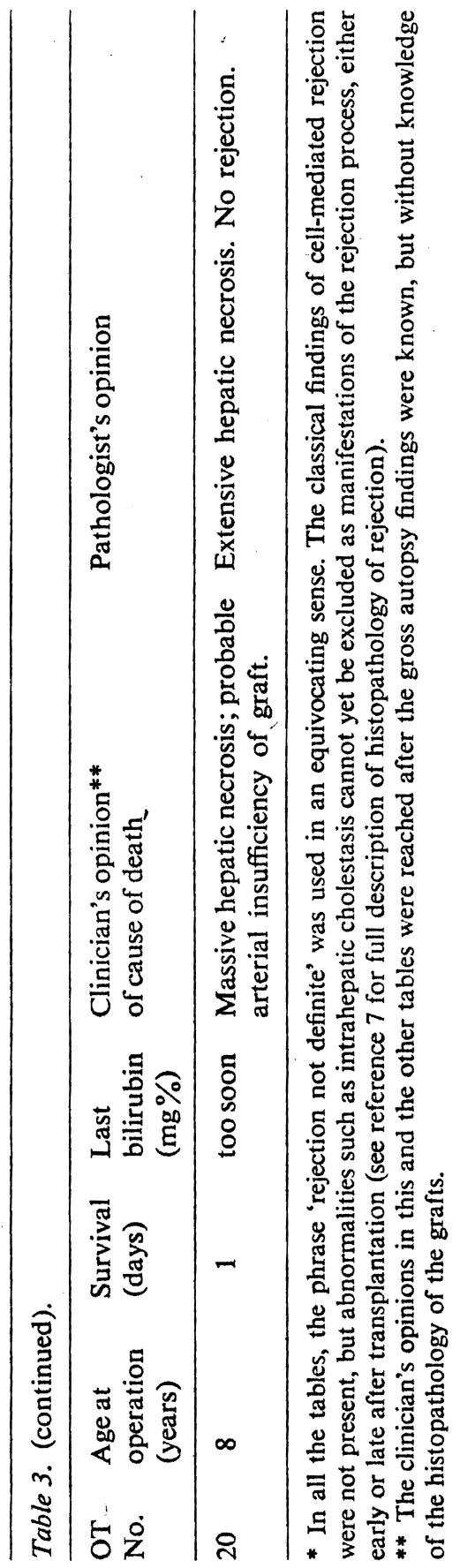


five other patients shown in table 3 died $33.8 \pm 28.9$ (S.D.) days postoperatively (OT 201 day; OT 319 days; OT 4161 days; OT 4434 days; and OT 57 64 days). Graft rejection accounted for only one of these failures. Technical complications accounted for three more fatalities. The fifth death after 64 days resulted from perforation of a posterior diverticulum in the ascending colon.

The two earliest deaths were of patients who had massive necrosis of the liver at autopsy, one (OT 20) and nine days (OT 31) postoperatively. Although the hepatic artery of one of these patients (OT 20) was patent at autopsy, it was thought that it had been distorted or kinked with consequent poor flow. Alternatively, the transplant may have sustained unrecognized damage from ischemia before, during or just after its removal from the donor and during implantation. The graft of the other patient (OT 31) was found at autopsy to be undergoing uncontrolled cellular rejection (fig. 2).

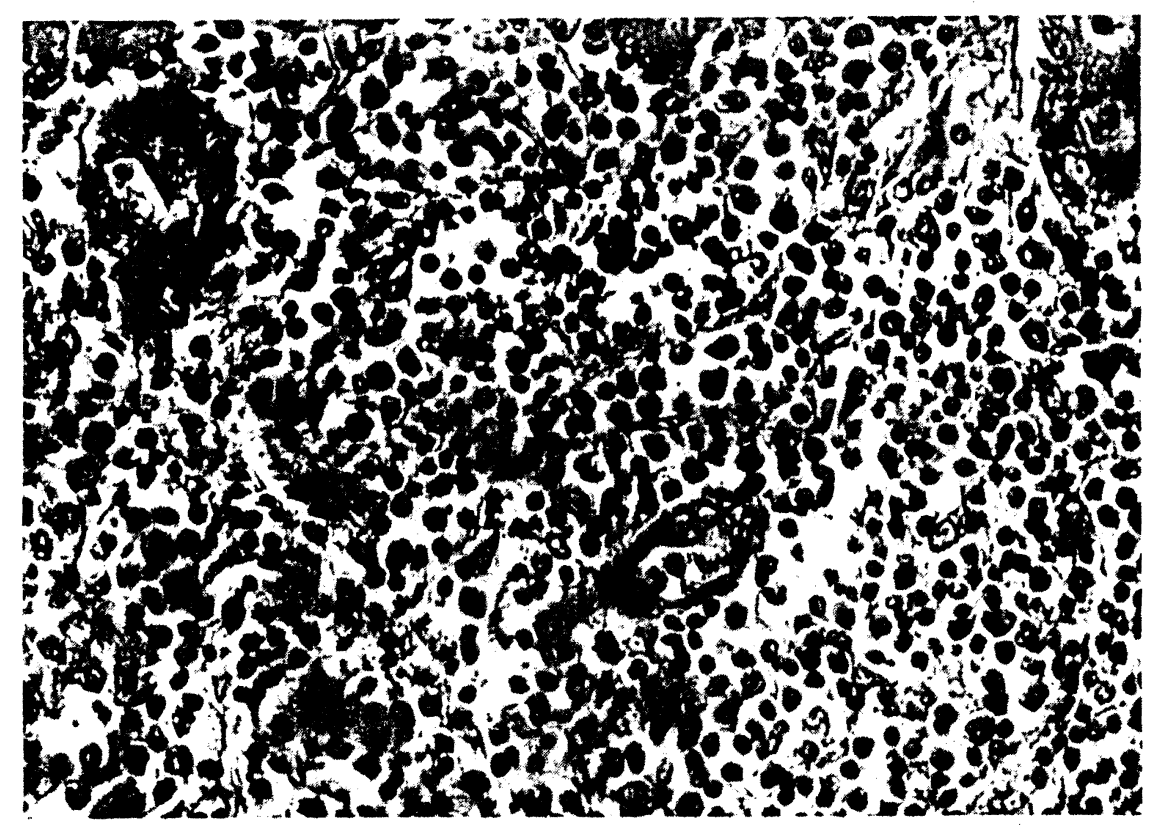

Fig. 2. Acute cell-mediated rejection (OT 31). The portal tract is diffusely infiltrated with lymphoid cells. Hematoxylin and eosin. $(\times 300)$

Two of the patients died 61 and 34 days after transplantation (table 3 ) as a consequence of partial obstruction of the homograft cystic duct following cholecystoduodenostomy. The results were dilatation of the intrahepatic 

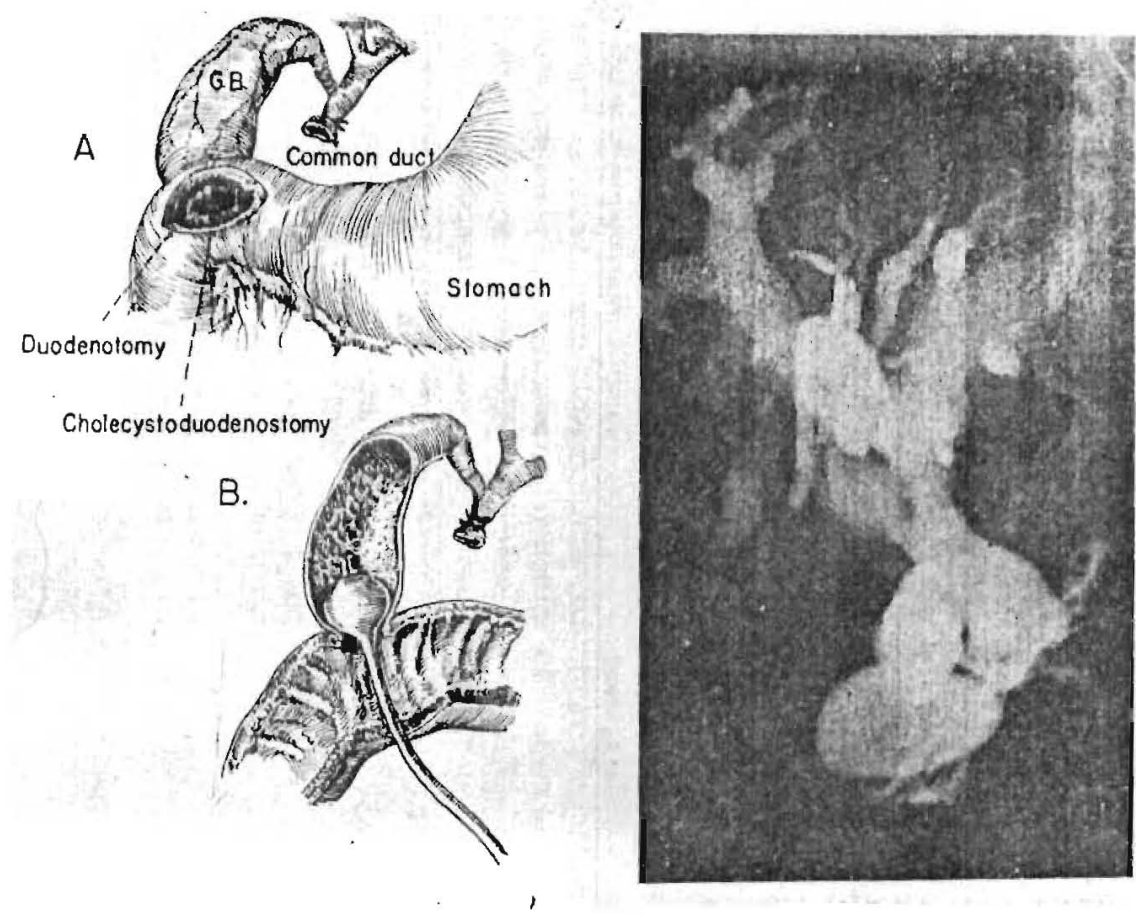

Fig. 3. Cholangiography of hepatic homograft. (A) and (B). Technique of dye injection through a duodenotomy and through the anastomosis. Right ... the obstructed duct system in patient OT 43. Operative and radiographic findings were almost identical in patient OT 41. In both cases cytomegalovirus of the cystic duct was present and may have been partially responsible for the complication. (By permission of Surgery 72: 604, 1972.)

biliary tree similar to that shown in figure 3 , and bacteremia that presumably originated from the liver. The complication was diagnosed at autopsy in one case after a right hepatic duct had ruptured first into an abscess and then into the subphrenic space (OT 44). The diagnosis in the other recipient (OT 41) was made at reoperation. Secondary conversion to choledochoduodenostomy was carried out, but too late. The grafts of these patients at autopsy had no evidence of rejection.

Late mortality. Nine of the 16 recipients had long survival (tables 1 and 4). Eight lived for at least a year and since a ninth child has reached the eight month mark with normal liver function, the one year survival is almost certain to be 56 per cent. Of the nine children who lived for a long time, six are still alive (table 4 ).

Two late deaths at 13 and 14 months wcre caused, at least in part, by 


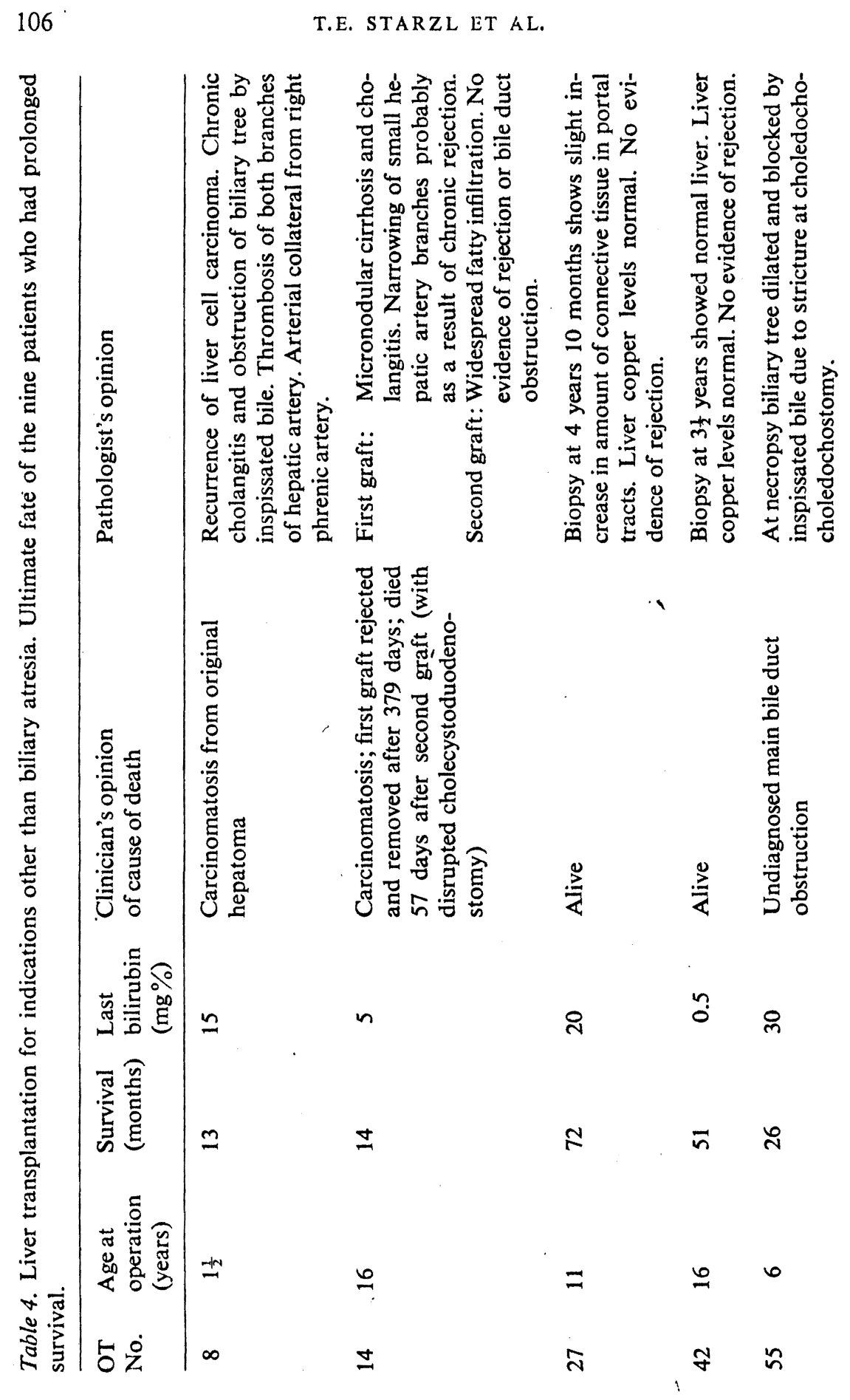


LIVER REPLACEMENT

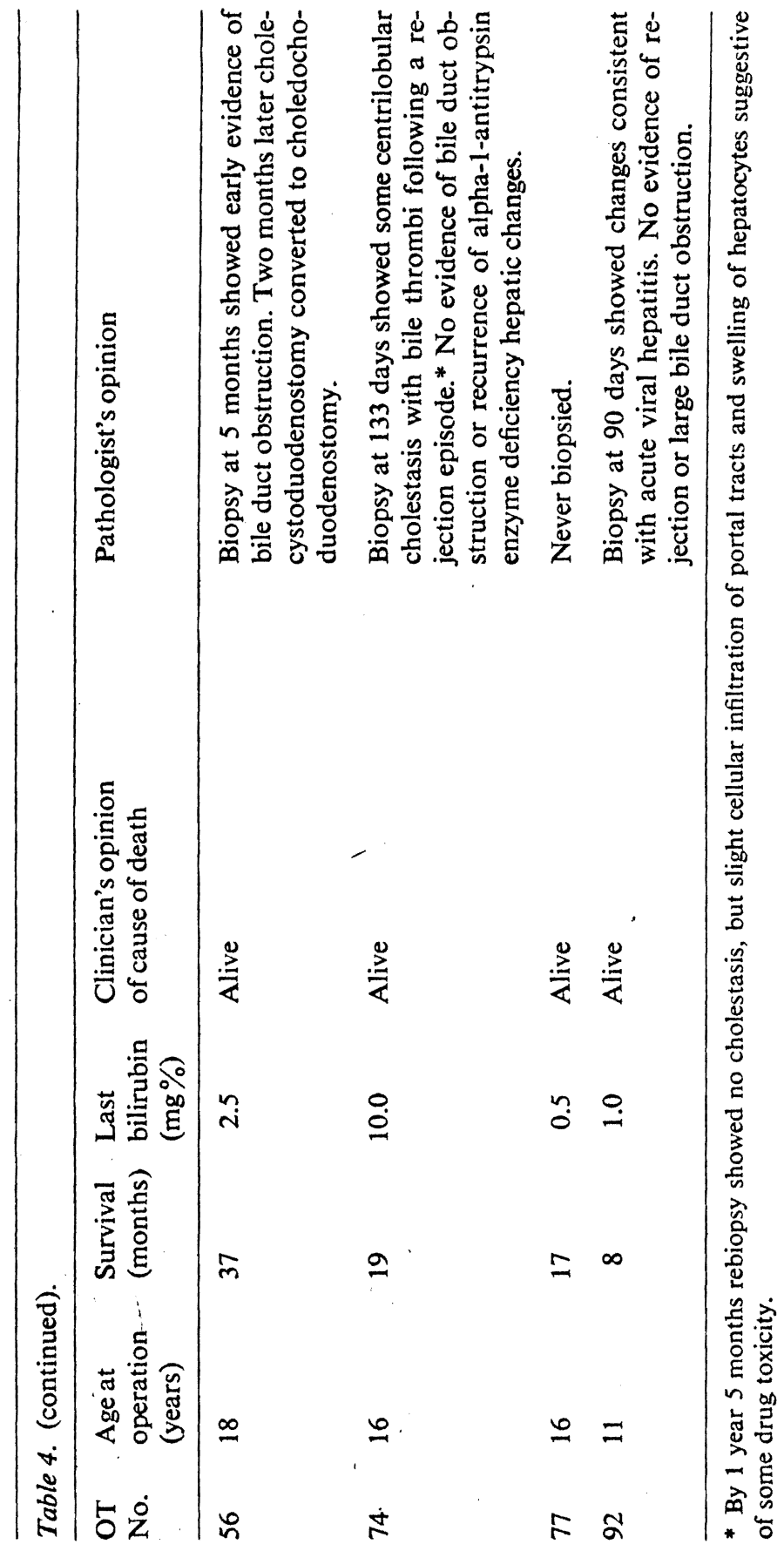


metastases from the hepatomas for which the transplantation had been originally performed (OT 8 and OT 14).

A third child whose original disease was chronic aggressive hepatitis died 2 years and 2 months after transplantation (OT 55). At autopsy, which was performed by Dr. Fred Germuth of St. Louis, Missouri, the total intra- and extrahepatic duct systems were crammed with chalk-like sludge. The complication was apparently caused by an underlying stricture at the choledochocholedochostomy that had been constructed more than two years earlier without T-tube drainage. The diagnosis was not made premortem in spite of two attempts to perform transhepatic cholangiography. Failure to enter the intrahepatic ducts was incorrectly taken as assurance against duct obstruction.

The liver in this tragic case had little evidence of rejection. The predominant findings were those of bile stasis. All the bile ductules were dilated and many lacked lining epithelium and were blocked by inspissated bile (fig. 4).

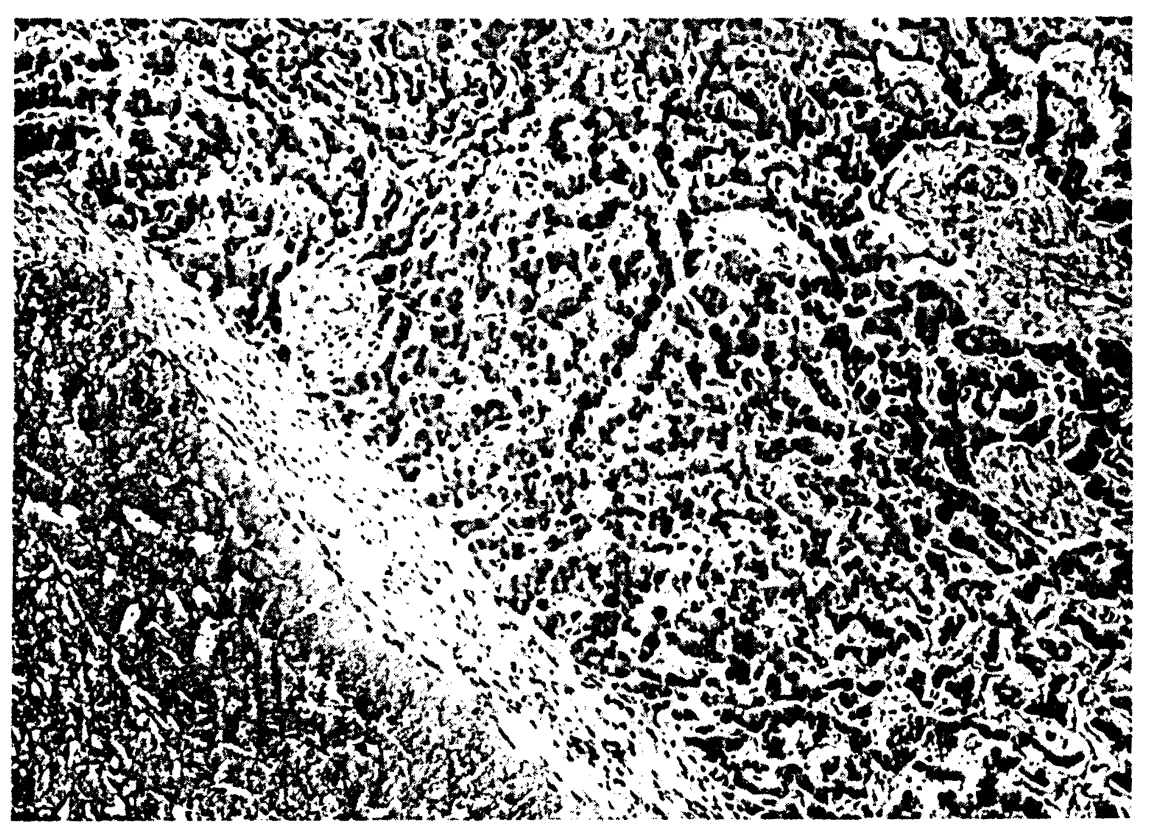

Fig. 4. Biliary obstruction caused by a stricture at the common duct anastomosis (OT 55). In the lower left of the picture, a greatly dilated bile ductule is filled with inspissated bile. Hematoxylin and eosin. $(\times 120)$ 
Some ductules had ruptured with extravasation of bile and subsequent focal fibrosis and calcification. There was also great narrowing of many of the hepatic artery branches by intimal thickening composed of smooth muscle cells and connective tissue. In several of the arteries the internal elastic lamina was ruptured. This arterial narrowing seemed to be mainly endarteritis caused by proximity to bile extravasation and cholangitis but chronic rejection may have contributed in part to the vascular obliterative changes.

\section{Cases of biliary atresia}

Mortality in the first half year. Twenty-nine of the 40 patients died early after transplantation (intraoperatively to 188 days). The mortality occurred in progressive waves to which specific etiologic factors selectively contributed at successive times.

Ten patients died $4.9 \pm 6.3$ (S.D.) days postoperatively (range intraoperatively to 20 days) because of failure to obtain a satisfactory technical result, or in one case because of a mistake in management (table 5). The most common accident was inability to arterialize the new liver, either because of hepatic artery thrombosis (three cases) or because of nonthrombotic occlusion of this vessel by compression or twisting (two cases). Operative and postoperative hemorrhage killed two more recipients and contributed to the death of a third. Portal vein thrombosis, obstruction of the venous outflow from the liver (caused by excessive cuff lengths of the vena caval anastomosis at the diaphragm) and blood volume mismanagement accounted for the other three failures.

hepatic artery thrombosis and wound hemorrhage, respectively) were of patients who were undergoing retransplantation after the first grafts had failed after 85 and 33 days for reasons that may not have involved rejection (see table 5). The primary graft of one patient (OT 70) appeared to have been irreversibly damaged by viral infection. The other primary graft (OT 52) was obtained from an anencephalic monster. It provided excellent function except for the persistence of jaundice. When the graft was removed after 85 days, intrahepatic ducts could not be found. It was considered possible that the donor had unrecognized intrahepatic biliary atresia.

A second group of five early deaths occurred $21.8 \pm 11.9$ (S.D.) days (range 7 to 36 days) after transplantation because of what the clinicians diagnosed as an inability to control rejection. Jaundice (table 6) and other perturbations of liver function tests showed hepatic failure but infections elsewhere were almost invariably present as a contributory cause of mortality. In one of the cases, a chimpanzee heterograft was used to replace a failed homograft after 


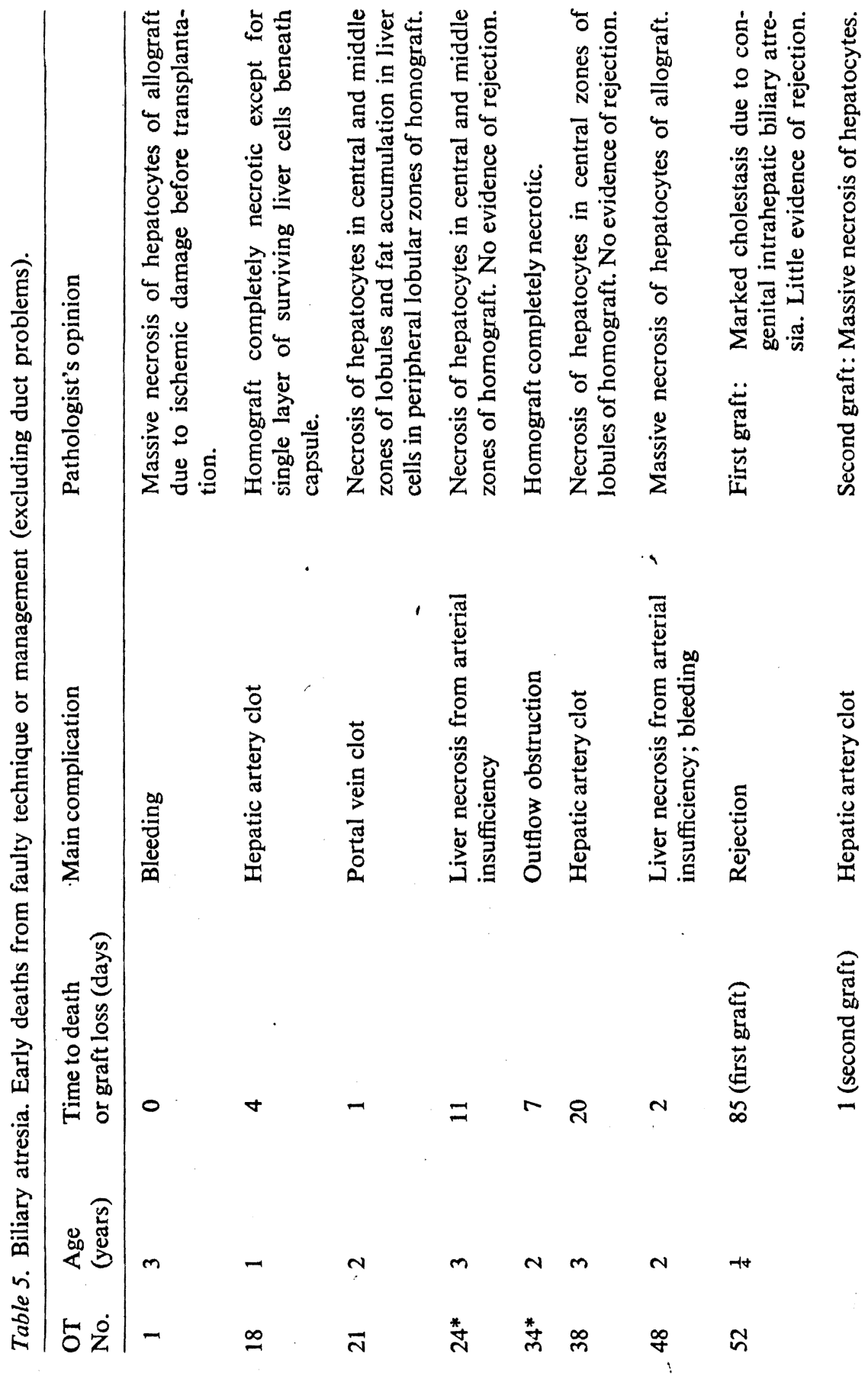




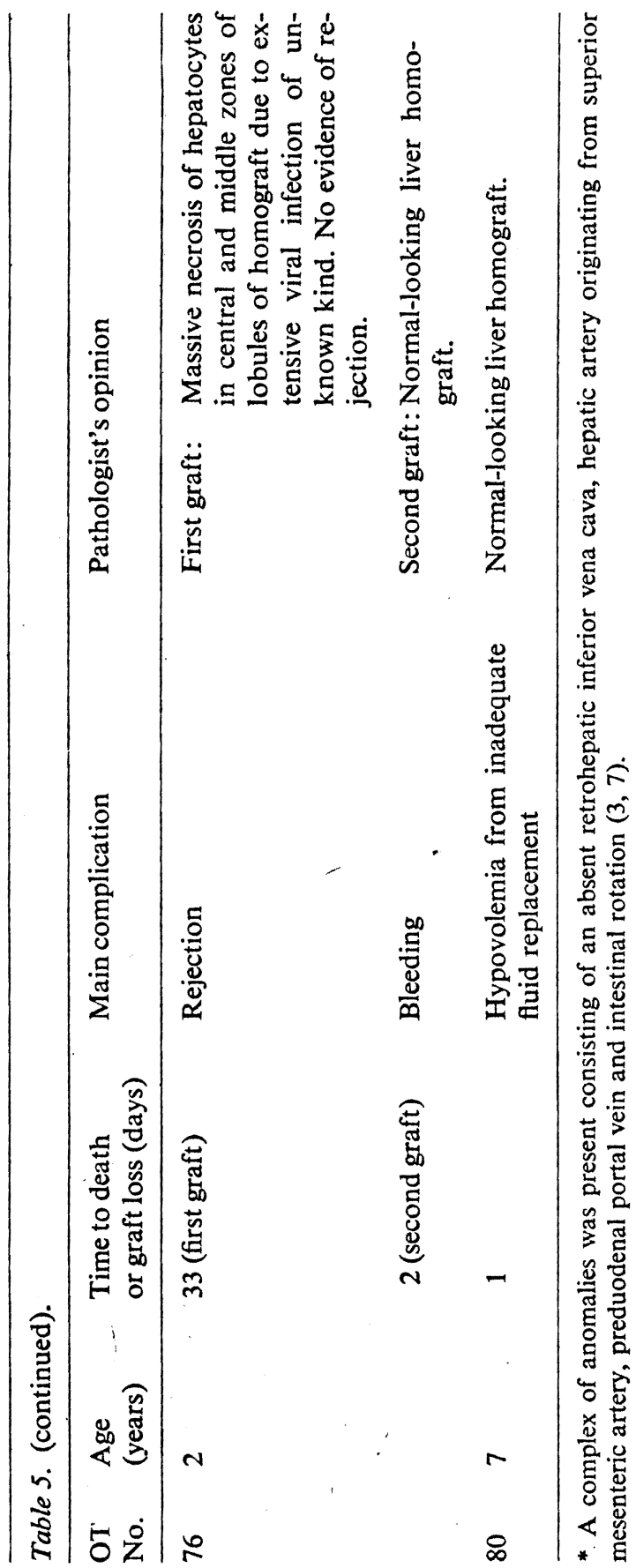




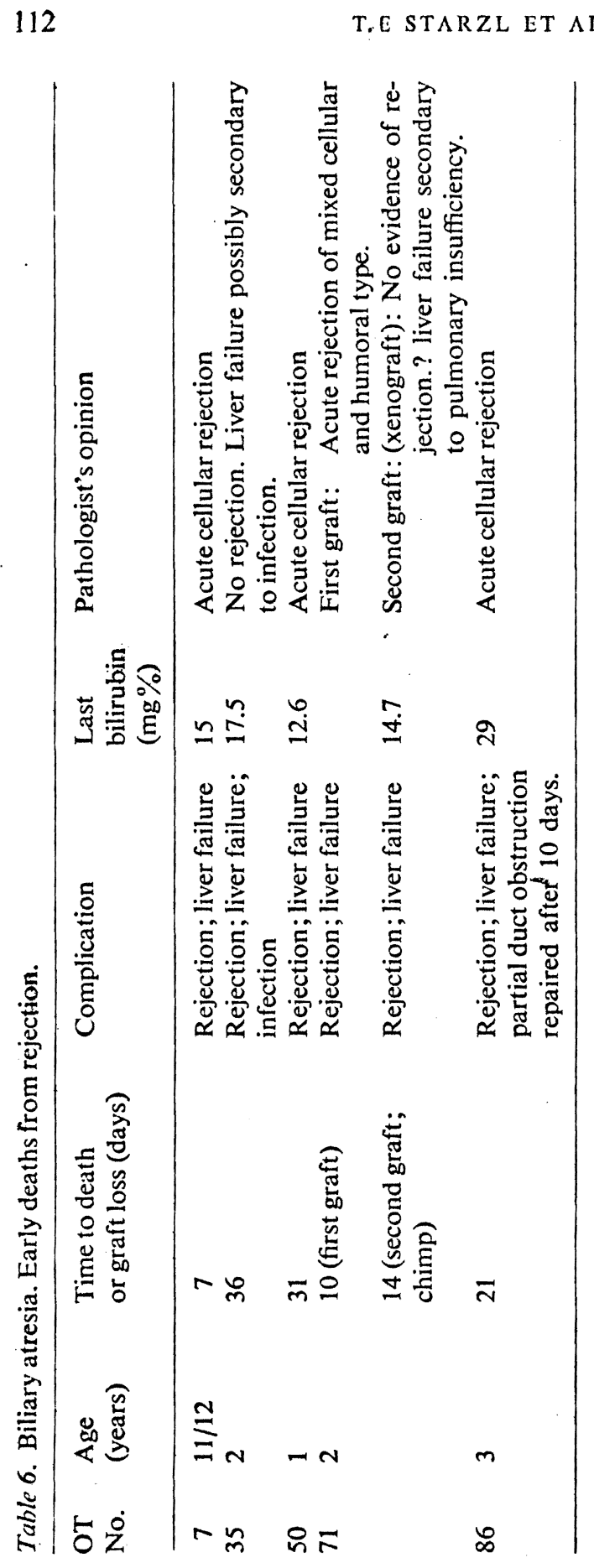




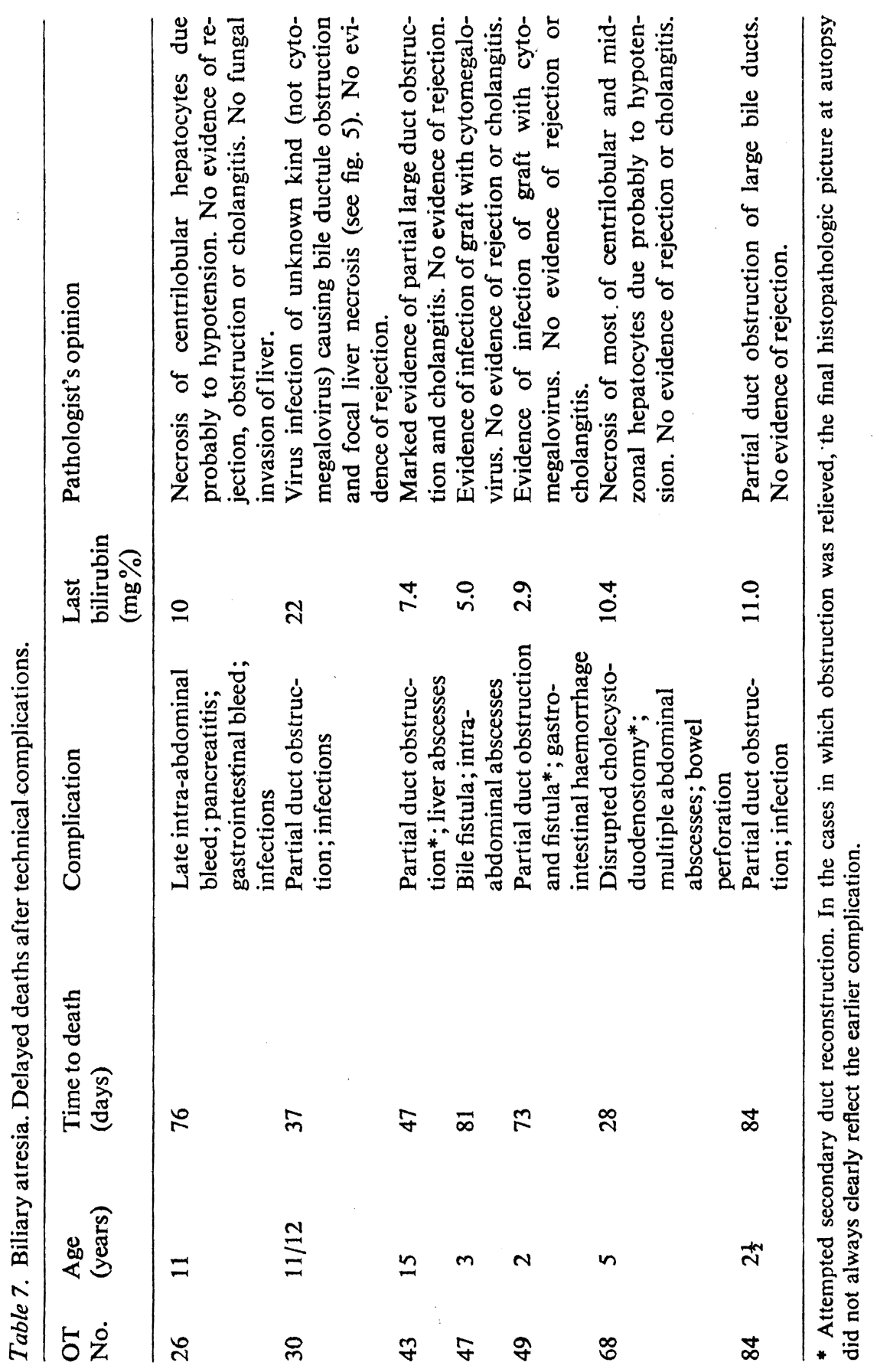


rejection of the first organ in 10 days. The chimpanzee liver was much less severely damaged than the homograft (table 6).

The histopathology of the transplants in these five cases is summarized in table 6 . The diagnosis of cell mediated rejection was usually confirmed but in case OT 35, the histopathologic findings were not compatible with rejection by customary criteria of diagnosis. In the other cases which had typical rejections there were large numbers of lymphoid cells infiltrating the portal tracts, and the areas around the central veins. The findings were like those shown in figure 2. Lymphocytes were present in smaller numbers in and around the sinusoids. Many of the lymphoid cells were large with pyroninophilic cytoplasm and mitoses were common. The portal tracts were oedematous and there was necrosis of hepatocytes in the central and middle zones of the lobules. The reticulin framework of the liver retained a lobular pattern but there was collapse of reticulin around the central veins. Cholestasis with bile 'thrombi' in the canaliculi was not a dominant feature.

Seven additional patients passed through the first few postoperative wecks in spite of very serious and eventually lethal technical complications (table 7). Six of the seven had defective biliary reconstructions, four with the kind of cystic duct obstruction shown in figure 3 after cholecystoenterostomy. Two other patients had bile fistulas, and in one of these cases there was also a delayed bowel perforation at the site where the intestine had been mobilized from its adhesion to the portal structures of the native liver. Only one of the seven patients, an 11 year old girl (OT 26), had a complication not related to the biliary tract of the homograft. In this case, an injury of the pancreatic tail apparently occurred during splenectomy. Later, this general area became the site of intra-abdominal hemorrhage and an invasive retroperitoneal fungal infection. Shortly after, gastrointestinal hemorrhage also occurred.

The histopathology of the homografts after $60.9 \pm 22.9$ (S.D.) days (range 28 to 84 days) in these mechanically flawed seven cases is summarized in table 7. Histopathologic evidence of partial obstruction of the large biliary ducts was the main feature in three of the seven liver allografts. In one of these cases (OT 30) the cause was a massive viral infection of the epithelial cells lining the biliary tree causing swelling, necrosis and shedding of the infected cells to form obstructing casts (fig. 5). Obstruction in the other two livers (OT 43 and OT 84) was due to the same cystic duct lesion shown in figure 3 . Two of the livers were severely infected with cytomegalovirus. Hypotension, associated with the patient's terminal illness, appeared to be the cause of the predominantly centrilobular necrosis in two other grafts. There was no evidence of rejection in any of these hepatic transplants. 


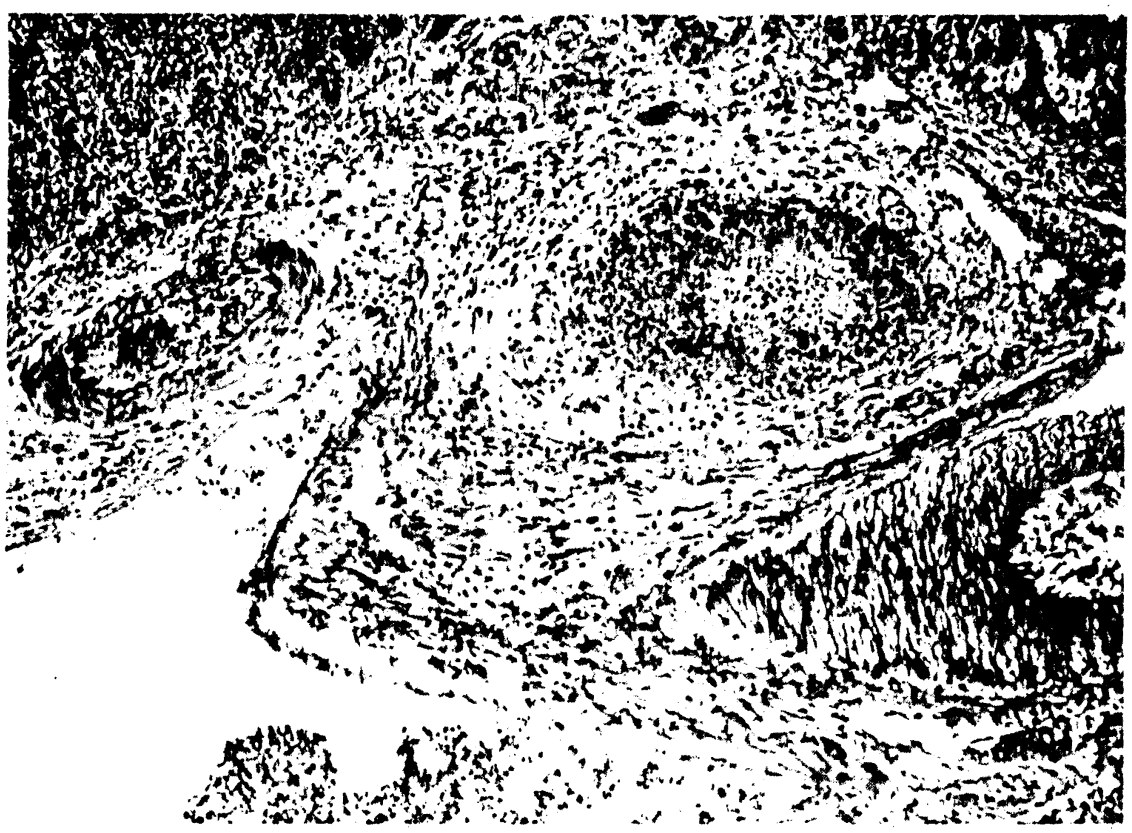

Fig. 5. Biliary obstruction caused by virus infection of the lining epithelium of the biliary ductules (OT 30). A portal tract containing a greatly narrowed bile ductule is in the upper right of the picture. Some of the lining epithelial cells are necrotic and others contain viral inclusions. Hematoxylin and eosin. ( $\times 120)$

The final wave of seven deaths came after $110 \pm 56.3$ (S.D.) days (range 51 to 186). All but one of these patients had abnormal liver function but the final event in each of their lives was uncontrolled infection with bacteria, fungi or viruses (table 8). Four of these seven delayed deaths were of patients who had a complication that has been called 'septic hepatic infarction' (7). Portions of the liver became necrotic and were invaded with bacteria from the intestinal tract. The four patients were tided over the immediate effects of the partial liver infarction, but they all eventually died with local plus systemic sepsis. Septic hepatic infarction is now thought to be due at least in part to under-immunosuppression and thus to be a manifestation of rejection. Mechanical factors such as twisting of the fragile hepatic arterial branches of these tiny recipients could contribute (7).

The livers from patients OT 37, 59 and 67 did not have regional infarctions; these patients had overwhelming systemic infections (table 8). 


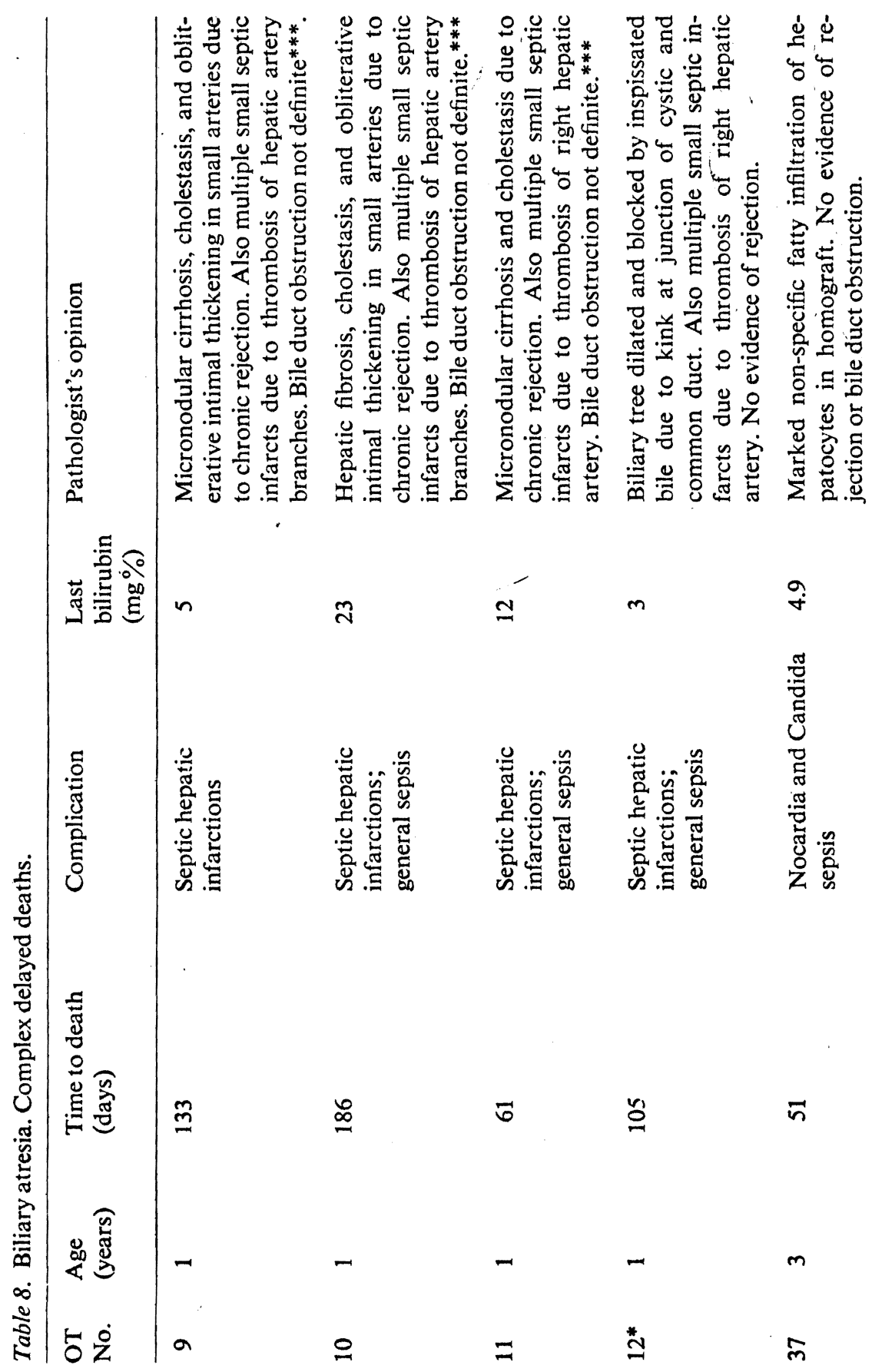


LIVER REPLACEMENT

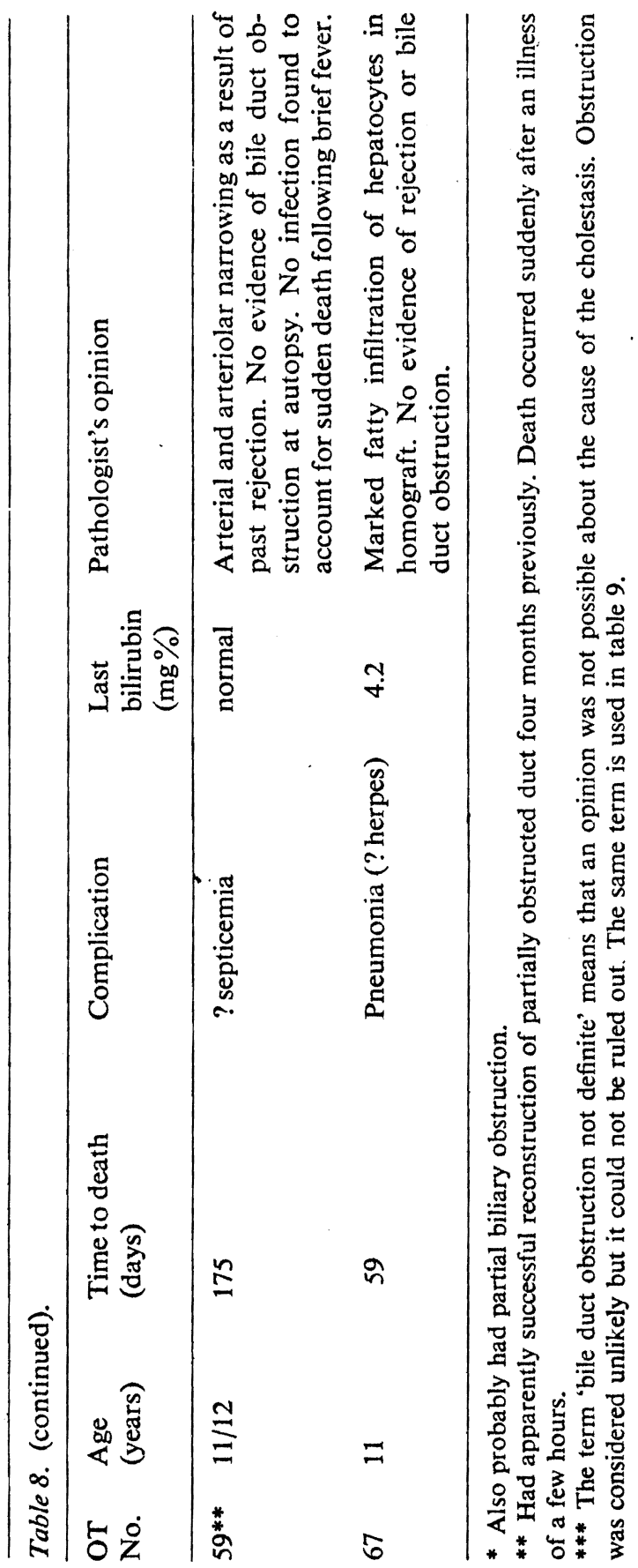


T.E. STARZL ET AL.

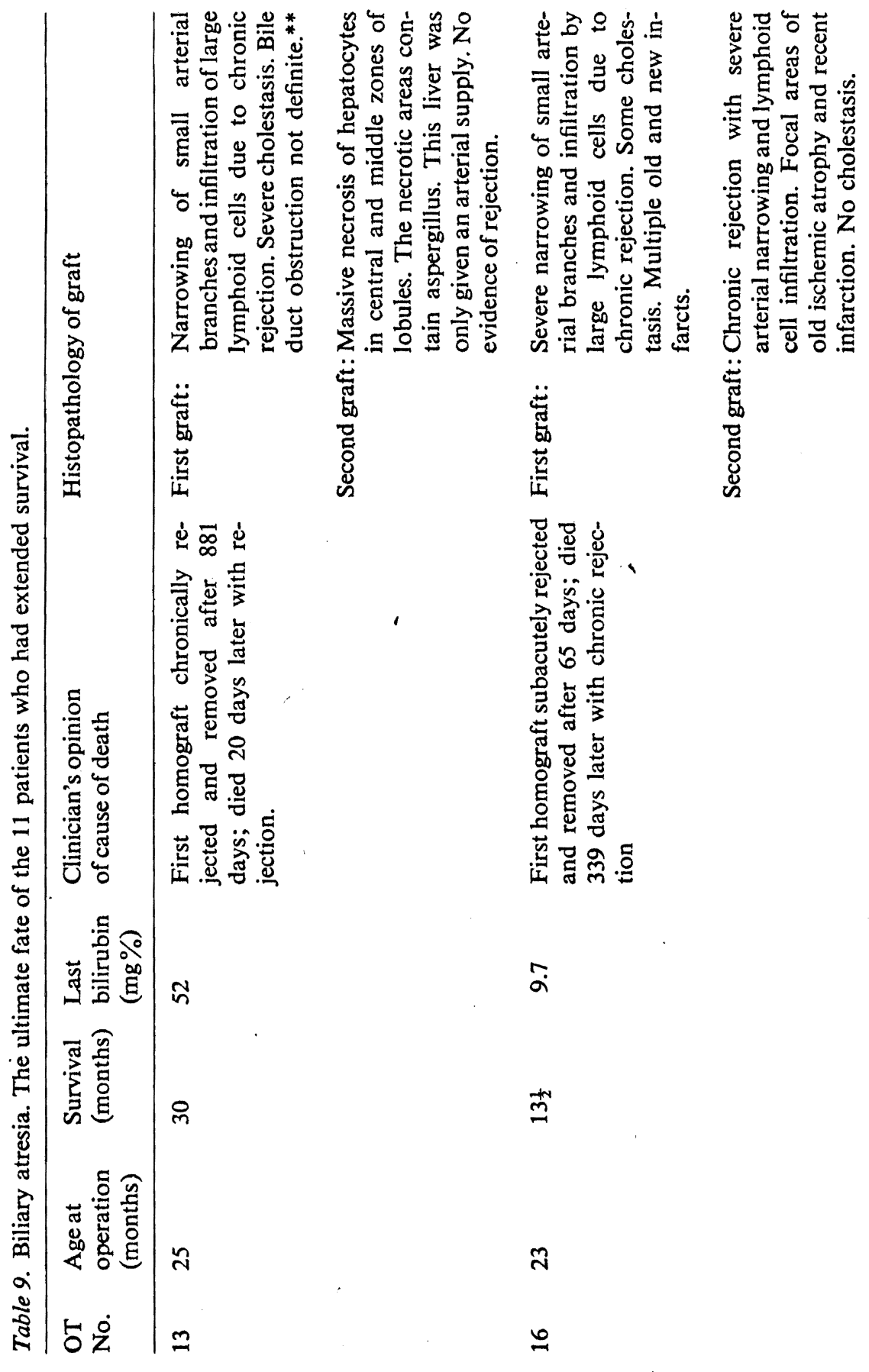




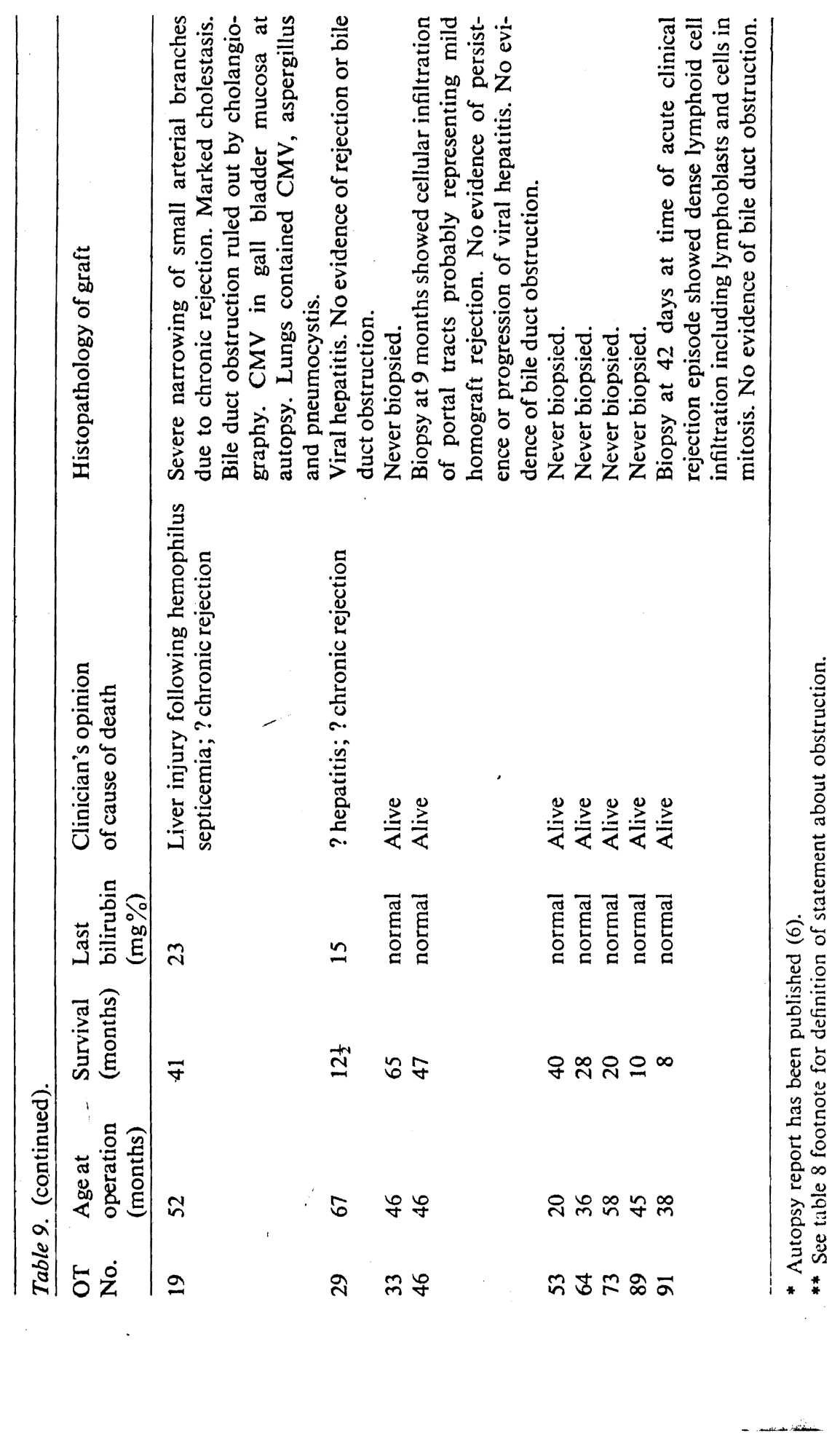


The histopathologic appearance of the seven livers recovered from 51 to 186 days postoperative is summarized in table 8 . Some evidence of chronic rejection was present in four of the seven livers and in three of these cases it was accompanied by obliterative intimal thickening of the small hepatic arteries (fig. 6). In one homograft kinking at the junction of the cystic and

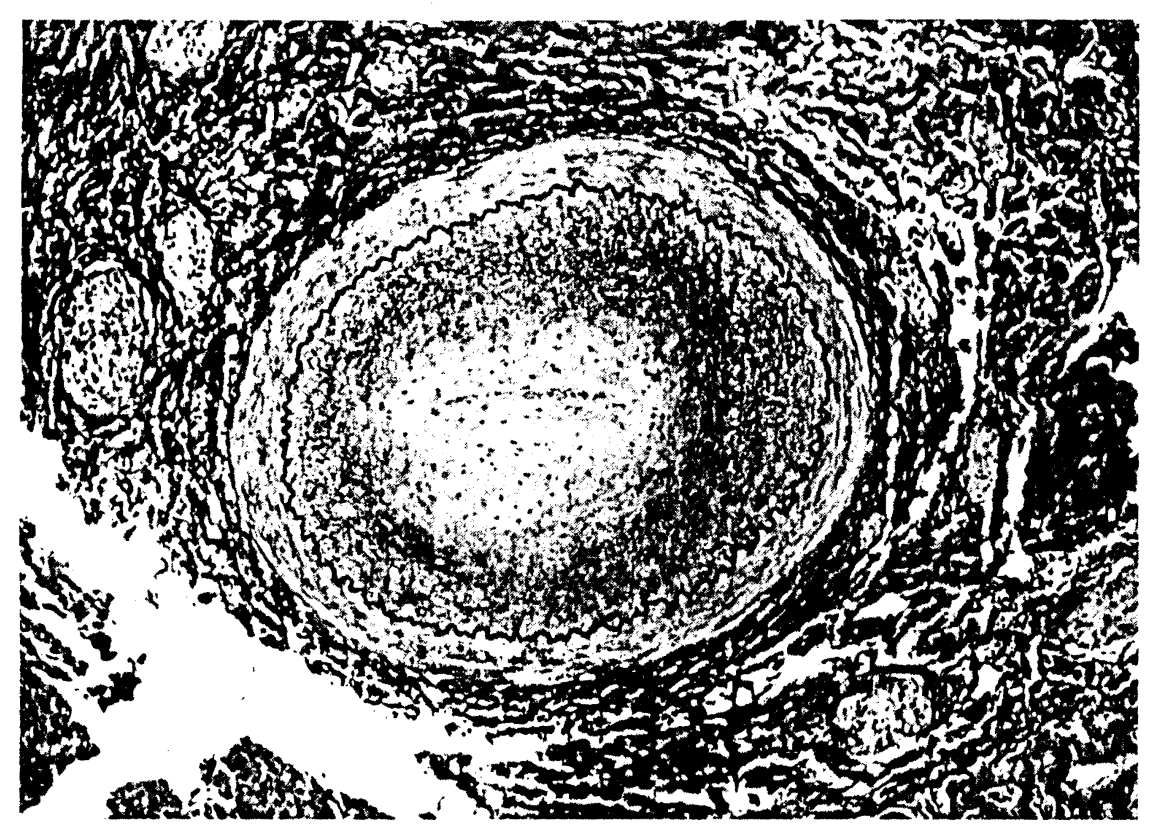

Fig. 6. Chronic rejection of a liver homograft (OT 19) almost $3 \frac{1}{2}$ years after transplantation. The small hepatic artery branch in a portal tract is completely occluded by a massively thickened intima. The internal elastic lamina is preserved. Elastic stain. $(\times 120)$

common duct had caused the biliary tree to become dilated and blocked by inspissated bile. The other two livers showed only marked fatty infiltration secondary to infection.

Late mortality. Of the 11 patients who lived for more than a half year, four subsequently died between $12 \frac{1}{2}$ and 41 (mean 24.2) months postoperatively for the reasons listed in table 9. All four children became jaundiced, but the reasons for this were probably multiple (table 9 ).

These four children were given a total of 6 grafts, since 2 of the recipients had retransplantation. The histopathologic findings in the six transplants are shown in table 9. The most important pathologic findings in 4 of the 5 
homografts that functioned for the longest time ( $2 \frac{1}{3}$ to 41 months) were chronic rejection with narrowing of the small arterial branches (fig. 6) and infiltration by lymphoid cells. The fifth chronically functioning liver (OT 29) showed the changes of viral hepatitis with no evidence of rejection or bile duct obstruction after more than a year. The second graft of patient OT 13 was given only an arterial supply. At 20 days after retransplantation it showed massive necrosis of hepatocytes in the central and middle zones of the lobules and infection by aspergillus.

The other seven patients are still alive (table 9) from 8 to 68 months postoperatively (mean 31.1 months). It is of interest that all seven survivors have normal bilirubins and that their liver function tests are normal in other measurable dimensions.

Graft biopsies were obtained early in the course of two of the seven patients who are still living. These showed cellular rejection, mild in one case and marked in the other. Both patients are well, 7 months and $3 \frac{1}{4}$ years later (OT 91 and 46) and after total survivals of 8 and 47 months respectively.

\section{EFFECT OF ORIGINAL DISEASE}

The only unequivocal effect of the original disease upon the transplant recipient was recurrence of the hepatomas in three cases. The patients with Wilson's disease were relieved of their excessive copper storage in extrahepatic tissues, and there has been no tendency for the homograft to accumulate copper (table 10). The pediatric victims of chronic agressive hepatitis,

Table 10. Biochemical findings pre- and posttransplantation in a patient with classical Wilson's disease.

\begin{tabular}{|c|c|c|c|c|c|}
\hline & Normal values & Pre-Op & 3 months & 17 months & 24 months \\
\hline Liver copper & $(<20 \mu \mathrm{g} / \mathrm{gm})$ & 184 & - & 45 & 27 \\
\hline Ceruloplasmin & $(22-49 \mathrm{mg} / 100 \mathrm{ml})$ & $1.0-1.7$ & 74 & 48 & 32 \\
\hline Urine copper & ( $<30 \mu \mathrm{g} / 24$ hours) & 540 & 119 & 80 & 87 \\
\hline SGOT & (3-27 Iu./L) & 25 & 70 & 25 & 15 \\
\hline Bilirubin & $(<1.0 \mathrm{mg} / 100 \mathrm{ml})$ & 2.9 & .4 & .64 & .5 \\
\hline
\end{tabular}

$\mathrm{HB}_{\mathrm{S}} \mathrm{Ag}$ negative, have not had an obvious recapitulation of the disease in their grafts although this has probably occurred in one adult who was $\mathrm{HB}_{\mathrm{S}} \mathrm{Ag}$ positive (2). 
In an earlier report on immunosuppressed kidney and liver recipients, the appearance of $\mathrm{HB}_{\mathrm{S}} \mathrm{Ag}$ in the serum seemed to be a permanent and consequently sinister finding (9). Therefore the observations on the course of posttransplantation $\mathrm{HB}_{\mathrm{S}} \mathrm{Ag}$ antigenemia which developed postoperatively for the first time in 5 of the chronic survivors were of great interest. Four (OT 29, 42, 55 and 77 ) of the patients had clinically apparent bouts of $\mathrm{HB}_{\mathrm{s}} \mathrm{Ag}$-associated hepatitis. A fifth patient (OT 46) had positive sera but had no associated alterations in liver function or clinical symptoms. Three of the 5 patients had subsequent clearing of the virus marker. One of the exceptions (OT 77) is shown in figure 7; although he recovered clinically he is now a carrier.

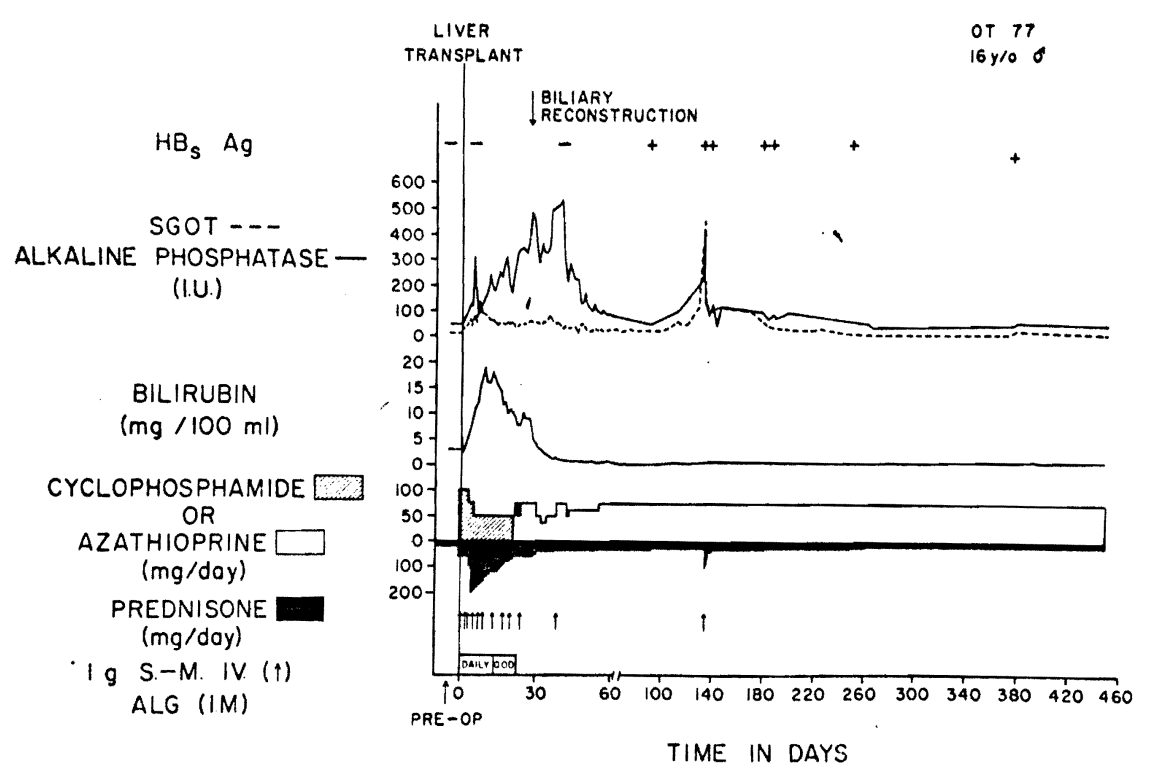

Fig. 7. Recovery after liver replacement for the indication of chronic aggressive hepatitis. The patient (OT 77) is the one whose postoperative transhepatic cholangiogram is shown in 8B. Jaundice persisted until the duct system was relieved of its obstruction by converting the initial Roux-enY cholecystojejunostomy to a choledochojejunostomy at the time indicated by the arrow. Note also that a bout of serum hepatitis complicated the recovery after about $2 \frac{1}{2}$ months. The patient recovered but became an $\mathrm{HBsAg}$ carrier.

The other patient (OT 29) with persistent $\mathrm{HB}_{\mathrm{g}} \mathrm{Ag}$ died after $12 \frac{1}{2}$ months and had findings of hepatitis in his graft (see table 9).

The poor results in 40 patients with biliary atresia, projected at a one year survival of $28 \%$, àre in contrast to the $56 \%$ figure in pediatric recipients with 
other preoperative diagnoses. Although atresia patients have other anomalies of which some may jeopardize the transplantation $(3,7)$ the presence of anomalies is not the main explanation for the difference in outcome between the two groups. Probably, the principal adverse factor has been the small size of the structures to be reconstructed in the younger and smaller population of the atresia subgroup, and a consequent increase in technical errors.

\section{PROSPECTS OF IMPROVEMENT}

The statistics given earlier showed that technical and mechanical complications were the main cause of early or late death in 22 cases, or the majority of all patients who have died. In an effort to ameliorate this situation, a number of changes were instituted in the autumn of 1973.

In an effort to minimize vascular accidents, microvascular techniques were used with increasing frequency for the portal venous and hepatic arterial anastomoses. Of even greater importance, techniques were upgraded to diagnose biliary obstruction and manage it effectively by reoperation according to the strategy outlined in an earlier publication (5).

Any patient who becomes jaundiced after transplantation or who develops unexplained bacteremia is now suspected of having biliary obstruction. Transhepatic cholangiography is performed, sometimes on multiple occasions (figs 8 and 9). The yield has been high since this aggressive and consistent policy was instituted. Of the last ten pediatric patients, three have required early conversion of Roux-en-Y cholecystojejunostomy to choledochojejunostomy because of the kind of partial or complete obstruction shown in figures 3 and $8 \mathrm{~B}$. All have survived and with prompt relief of jaundice. A fourth patient, who had the same complication plus a bile leak from the ligated common duct (fig. $8 \mathrm{C}$ ), died before reoperation was possible (table 7, OT 84$)$. Six $(60 \%)$ of the last ten pediatric recipients are still alive after 8 to 20 months. Without aggressive reintervention this figure would have been $30 \%$.

Even if all the technical problems are solved, it now seems to us that between one and two of every ten liver homografts is going to be rejected early in spite of the best immunosuppression available today. In such cases, early retransplantation will have to be considered after the differential diagnosis of duct obstruction is ruled out, and providing other etiologic factors such as hepatitis or drug hepatotoxicity are not implicated.

The indolent pattern of an inexorably rejecting graft is shown in figure 9 , 

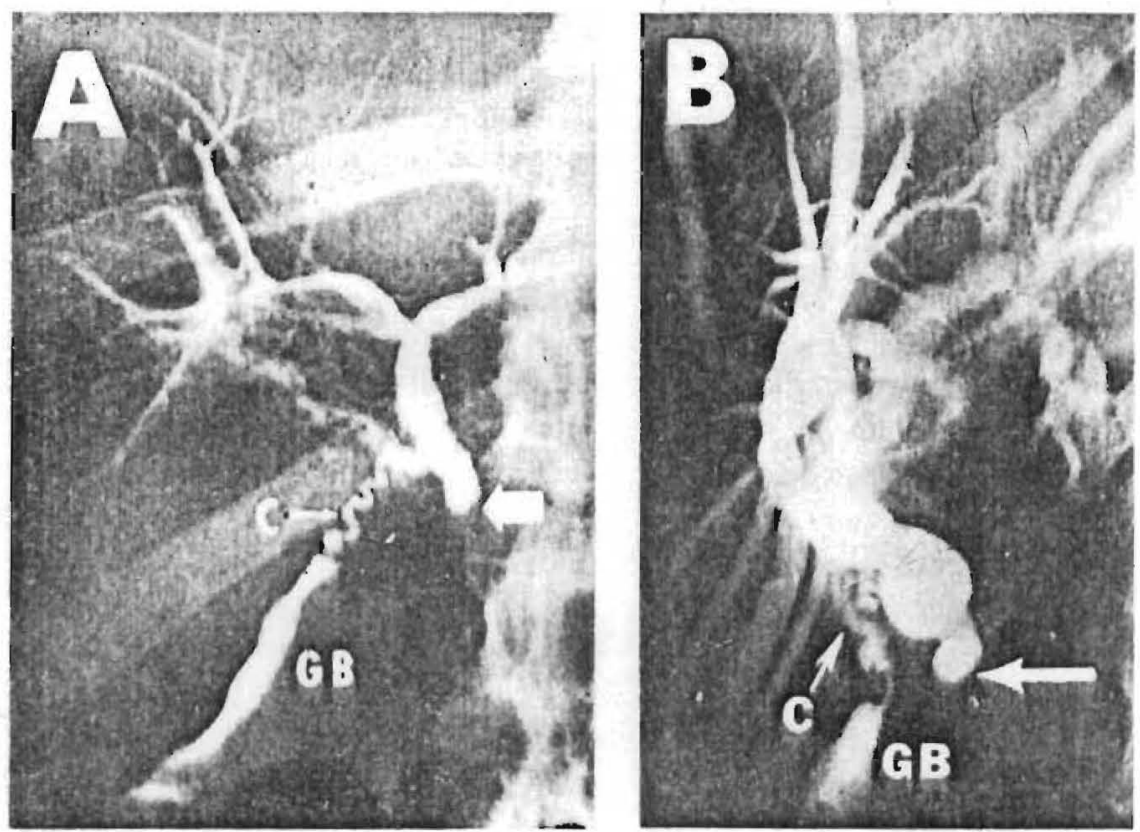

Fig. 8. Transhepatic cholangiography in 3 patients: (A) The demonstration of a nondilated duct system prompted intensification of steroid therapy. Arrow - ligated common bile duct. (B) partially obstructed duct system. The patient was reoperated and the cholecystojcjunostomy (see fig. 1B) was converted to the cholcdochojejunostomy shown in figure $1 \mathrm{C}$. The ultimate result was perfect (see fig, 7). (C) Obstructed cystic duct syndrome plus bile extravasation near distal ligated common bile duct (arrows). This child died of generalized sepsis before reoperation could be carried out. $C$ : cystic duct; GB: gallbladdcr.

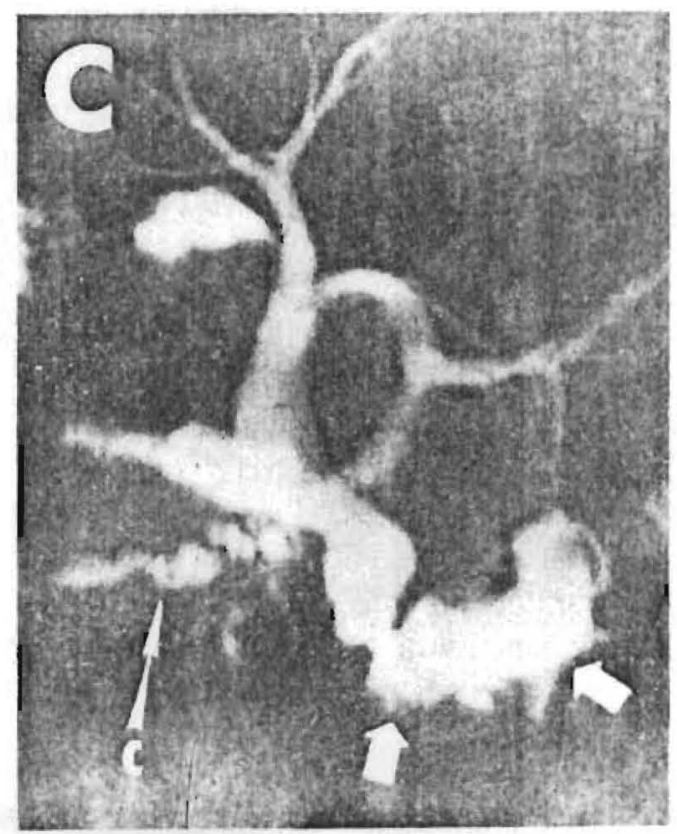


OT 98

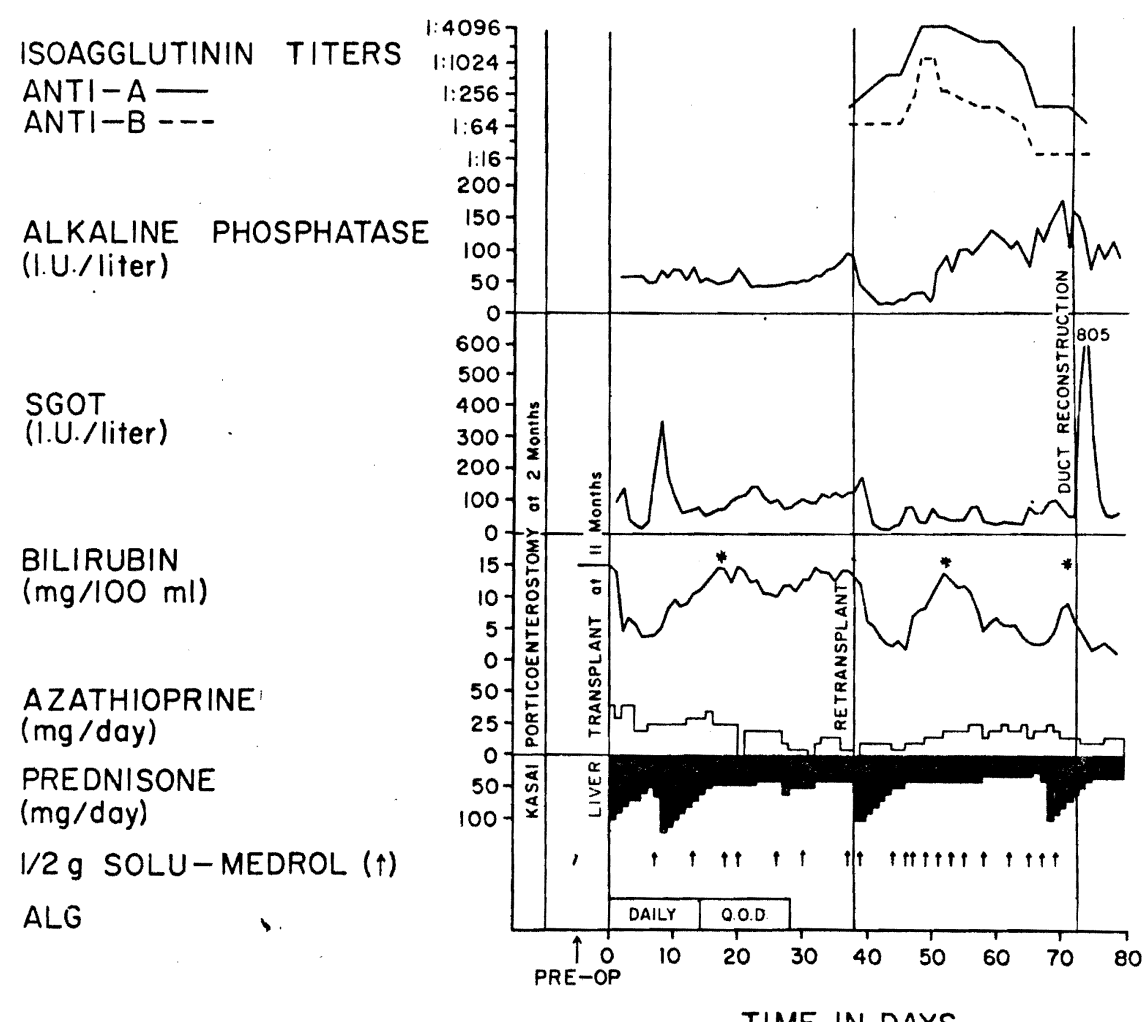

TIME IN DAYS

Fig. 9. Uncontrolled rejection after orthopic liver transplantation (OT 98) in a 9 month old child who had had an unsuccessful porticoenterostomy at the age of 2 months. The rejected primary transplant was removed after 38 days and replaced with another liver. The recipient was $O$ blood type as was the first donor. The second donor was $A$ blood type. Note the prodigious increase in the anti-A isoagglutinins which did not have an obvious adverse effect. The duct system of the second graft became obstructed, and was relieved by converting the cholecystojejunostomy to choledochojejunostomy. The asterisks indicate the performance of transhepatic cholangiograms. The first two were normal but the third revealed obstruction.

with jaundice that is predominantly obstructive and with serum transaminases that are modestly elevated. If the biliary reconstruction is proved sound, there can be little doubt of the diagnosis, and reexploration must be performed as soon as a liver becomes available. In the case depicted (fig. 9) the graft weighed more than 500 grams, an estimated fivefold increase from 
its weight at its insertion a month earlier. The second graft for this $\mathrm{O}$ recipient was from an A donor. In spite of this red blood group mismatch, the organ functioned much better than the red blood group compatible first organ.

Since cadaveric organ donors may not be available at times of desperate need, cautious exploration of chimpanzee liver heterotransplantation is going to be necessary as a possible way out of what otherwise rapidly becomes a hopeless situation. Three liver heterotransplantations have been performed $(5,7)$ with maximum survival of only two weeks, but with encouragingly minor histopathologic findings in the grafts (for example, see table 6, OT 71).

PORTICO-ENTEROSTOMY AND TRANSPLANTATION IN

BILIARY ATRESIA

Some of the patients with biliary atresia whom we have recently seen have had earlier portico-enterostomy procedures that failed. The prior performance of the Kasai operation has not jeopardized transplantation. In three cases of our experience the previous construction of an isolated Roux-en-Y jejunal segment has proved to be a significant advantage since the Roux limb has been used to accept the graft biliary drainage (figs. 9 and 10).

Although the Kasai procedure apparently alters the natural history of biliary atresia in some cases, the operation will be curative only rarely. Altman and Lilly have shown that progressive cirrhosis is almost invariable, even in those patients whose jaundice has been completely relieved by porticoenterostomy (1). Although some of these children probably will have their lives prolonged, eventually almost all will become candidates for transplantation.

Thus, porticoenterostomy and liver transplantation are not competitive procedures. They should be viewed as complementary in the continuum of care that is slowly evolving for children with biliary atresia. If it is to be effective, porticoenterostomy has been urged by its proponents before the age of three months when liver transplantation is not yet a good possibility. Liver replacement is reserved for a later time. Examples of this approach are shown in figures 9 and 10.

In our three patients who had liver transplantation after previous Kasai procedures, one died in less than a month and the other two are still alive after 3 and 20 postoperative months. 
SGOT

(I.U./liter)

BILIRUBIN

(mg/100 ml)

CYCLOPHOSPHAMIDE $\square$

OR

AZATHIOPRINE

(mg/day)

PREDNISONE

(mg/day)

$1 / 2 \mathrm{~g}$ SOLU-MEDROL ( $\uparrow)$

ALG

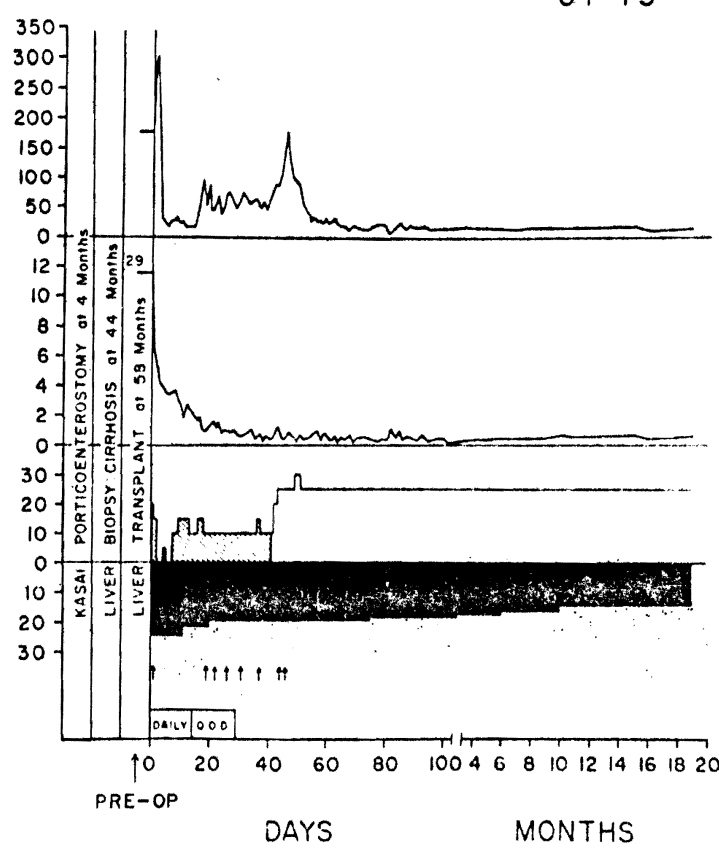

Fig. 10. The course of a child who had a failed Kasai operation but who ultimately was effectively treated with liver replacement. The successive use of the porticoenterostomy and liver transplant is also illustrated in figure 9.

\section{SUMMARY}

In the decade ending in the fall of 1974 , liver replacement was attempted in 93 patients of whom 56 were 18 years old or younger. Twenty of the 56 pediatric recipients had survival of eight months or more, 17 lived for at least a year and 13 are still alive. The longest survival is now six years.

The results with biliary atresia were poorer than if the original disease was something other than atresia. In both subgroups, the greatest cause for the high failure rate was a variety of technical misadventures of which complications of bile duct reconstruction headed the list. Failure to control rejection was a far less common cause of death. Suggestions to improve the results were made. 


\section{REFERENCES}

1. Altman, R. P. and J. R. Lilly, Ongoing cirrhosis after successful porticoenterostomy in infants with biliary atresia. J. pediat. Surg. 10:685-691 (1975).

2. Corman, J. L., C. W. Putnam, S. Iwatsuki, A. G. Redeker, K. A. Porter, R. L. Peters, G. Schroter and T. E. Starzl, Liver homotransplantation for chronic aggressive hepatitis, Australia antigen positive. Gastroenterology. In press.

3. Lilly, J. R. and T. E. Starzl, Liver transplantation in children with biliary atresia and vascular anomalies. J. pediat. surg. 9: 707-714 (1974).

4. Starzl, T. E., Experience in Renal Transplantation (W. B. Saunders, Philadelphia 1964).

5. Starzl, T. E., M. Ishikawa, C. W. Putnam, K. A. Porter, R. Picache, B. S. Husberg, C. G. Halgrimson and G. Schroter, Progress in and deterrents to orthotopic liver transplantation; with special reference to survival, resistance to hyperacute rejection, and biliary tract reconstruction. Transplant. Proc. 6 (suppl. 1): 129-139 (1974).

6. Starzl, T., K. A. Porter, G. Schroter, J. Corman, C. G. Groth and H. L. Sharp, Autopsy findings in a long-surviving liver recipient. New Engl. J. Med. 289: 82-84 (1973).

7. Starzl, T. E. and C. W. Putnam, Experience in Hepatic Transplantation (W. B. Saunders, Philadelphia 1969).

8. Starzl, T. E., C. W. Putnam, C. G. Halgrimson, G. T. Schroter, G. Martineau, B. Launois, J. L. Corman, I. Penn, A. S. Booth, Jr., and C. G. Groth, Cyclophosphamide and whole organ transplantation in humans. Surg. Gynec. Obstet. 133: 981-991 (1971).

9. Torisu, M., T. Yokoyama, H. Amemiya, P. F. Kohler, G. Schroter, G. Martineau, I. Penn, W. Palmer, C. G. Halgrimson, C. W. Putnam and T. E. Starzl, Immuncsuppression, liver injury and hepatitis in renal, hepatic, and cardiac homograft recipients: With particular reference to the Australia antigen. Ann. Surg. 174: 620-639 (1971). 